\title{
CHOREA GRAVIDARUM- A RARE CASE REPORT
}

\author{
Anjani Edupuganti' ${ }^{1}$, Soumya R. Patil2, Gangambika N. Nisty33, Shradha ${ }^{4}$
}

${ }_{1}^{1}$ M. S, Department of Obstetrics and Gynaecology, Mahadevappa Rampure Medical College, Gulbarga, Karnataka, India. 2M. S, Department of Obstetrics and Gynaecology, Mahadevappa Rampure Medical College, Gulbarga, Karnataka, India. 3M. S, Department of Obstetrics and Gynaecology, Mahadevappa Rampure Medical College, Gulbarga, Karnataka, India. ${ }_{4}^{4}$ M. S, Department of Obstetrics and Gynaecology, Mahadevappa Rampure Medical College, Gulbarga, Karnataka, India.

HOW TO CITE THIS ARTICLE: Edupuganti A, Patil SR, Nisty GN, et al. Chorea gravidarum- a rare case report. J. Evolution Med. Dent. Sci. 2019;8(05):336-338, DOI: 10.14260/jemds/2019/73

\section{PRESENTATION OF CASE}

A 25 years old female G2P1D1 belonging to low socioeconomic group from a rural place presented to emergency department with h/o one and a half months of amenorrhoea with increased abnormal involuntary movements of all limbs since 10 days.

History was elicited from her mother who stated that the patient was asymptomatic before and then she started abruptly developing involuntary movements, first in the left upper limb then progressed to all the limbs and also involving tongue. The movements were continuous, irregular and progressive in nature.

She was married one and a half years back, nonconsanguineous marriage. Her past menstrual history was regular cycle and her LMP-20-5-2014, EDD 27-02-2015.

P1D1- conceived spontaneously, had induction delivery at 29 weeks' gestation, for severe PIH with imminent eclampsia at a private hospital in Gulbarga. Baby died 4-5 days after birth.

Patient had h/o syncopal attack and fall 10 years back which was associated with fever and headache for which she had taken treatment at a local hospital. No h/o of any drug prophylaxis taken after that.

2 year later patient was taken to a private hospital with minimal involuntary movements involving only the left upper limb. The movements were irregular in nature slowly progressing to involve all the four limbs. There she was diagnosed as SLE with chorea with lupus nephritis on routine investigations. There was one episode of seizures at that time, generalised tonic clonic type, associated with loss of consciousness lasting for 4-5 mins, not associated with urinary or bladder incontinence. Patient was put on treatment since then. Patient was on Tab. Prednisolone $5 \mathrm{mg}$ (since 8 years), Tab. Eptoin (For 2 months), Tab. Hydroxychloroquine (Since 8 years). No history of fever with sore throat in the past, however she denied using inj. Penicillin for long time.

There was no history of any psychiatric illnesses in the past and no history of any drug intake. Her family history was unremarkable.

'Financial or Other Competing Interest': None.

Submission 21-01-2018, Peer Review 18-01-2019,

Acceptance 25-01-2019, Published 04-02-2019.

Corresponding Author:

Anjani Edupuganti,

D/o. Dr. E. Tagore Prasad,

Samatha Nursing Home,

Bhadrachalm-507111, Bhadrabri Kothugeden District,

Telangana, India

E-mail: anjaniedupuganti@gmail.com

DOI: $10.14260 /$ jemds/2019/73

\section{On Examination}

On general examination, she was average built and nourished of normal intellect. She was unconscious, uncoherent and not well oriented to time, place and person and her heart rate and blood pressure was normal. Pallor $(+++)$, no icterus, cyanosis, clubbing, lymphadenopathy, no swelling in the neck.

\section{Systemic Examination}

In cardiovascular system pansystolic murmur heard in the mitral area. Respiratory system- normal vesicular breath sounds heard. Nervous system- She had abnormal facial movements, tongue was darting even at rest, abnormal, irregular, jerky movements present in the both upper and lower limbs. Tone, power of muscles of all limbs decreased. Superficial reflexes are present and deep reflexes are absent. Sensory system and all cranial nerve examinations were normal. There were no cerebellar signs and signs of meningeal irritation. Uterus is soft.

\begin{tabular}{|c|c|}
\hline Haemoglobin & $7 \mathrm{gm} \%$ \\
\hline Total Leukocyte Count & 4500 cells $/ \mathrm{mm}^{3}$ \\
\hline Platelets & 100000 cells $/ \mathrm{mm}^{3}$ \\
\hline ESR & $80 \mathrm{~mm} / \mathrm{hr}$ \\
\hline C Reactive Protein & positive \\
\hline Serum Calcium & $9 \mathrm{mg} / \mathrm{dL}$ \\
\hline Serum Creatinine & $1.8 \mathrm{mg} / \mathrm{dl}$ \\
\hline Serum Urea & $35 \mathrm{mg} / \mathrm{dl}$ \\
\hline Urine Routine- Albumin & $2+$ \\
\hline Casts & Red Blood Cell Casts Present \\
\hline Anti-Nuclear Antibody & Positive \\
\hline Anti Streptolysin O & Positive \\
\hline Throat Swab Culture & Positive \\
\hline Liver Function Tests & Normal \\
\hline Thyroid Profile & Normal \\
\hline \multicolumn{2}{|c|}{ Table 1. Investigations } \\
\hline
\end{tabular}

Ultrasound shows single live intrauterine pregnancy of 6 weeks and 5 days with B, 'L Grade II lupus nephritis (Mesangioproliferative glomerulonephritis).

2D-Echo- Chronic RHD with moderate MS and MR.

Chest X-ray-Normal study.

MRI- Shows normal study.

\section{CLINICAL DIAGNOSIS}

1. Chorea Gravidarum Secondary to Underlying Rheumatic Heart Disease

2. SLE. 


\section{DIFFERENTIAL DIAGNOSIS}

The differentials which were considered on history and examination were chorea gravidarum, rheumatic, systemic lupus erythematosus, primary anti-phospholipid antibodies, drug induced.

The absence of associated symptoms of fever, coryza helped in excluding viral encephalitis. There was no family history of Huntington disease. No history of any drug usage, so drug induced can be ruled out. The slit-lamp examination helped exclude Wilson disease.

The positive history SLE and precipitation of events in previous pregnancy and pregnancy loss and 2D echo showing CHRD in this pregnancy indicated toward the likelihood of chorea gravidarum which was SLE and rheumatic in origin.

In a young patient, with previous history of SLE thrombophilic tendencies should be considered. This patient was normotensive but increased levels of $\mathrm{C}$ reactive protein and ESR with anti-nuclear antibody and ASO titre positive and throat swab culture positive with altered renal parameters. She was SLE with lupus nephritis.

\section{DISCUSSION OF MANAGEMENT}

The patient was admitted in an isolated ward and after proper hydration and one dose of benzyl penicillin 1.2 million units, Pregnancy was terminated as follows- Tab. Mifepristone $200 \mathrm{mg}$ - day 1 - Tab. Misoprost $800 \mu \mathrm{g}$ - day 4 , 60 hrs later -200 per vaginally. -200 orally- Patient expelled the products of conception from day 4 onwards with passage of clots. Repeat USG Day 6: - Normal study. No products of conception visualised. Her symptoms subsided. She was discharged on Tab. prednisolone $5 \mathrm{mg}$ BD, Tab. Revacon (Tetrabenazine) $0.25 \mathrm{mg}$ BD, Tab. Haloperidol $1.5 \mathrm{mg}$ BD, Tab. dosage increased from Day 5 to Tab. prednisolone $5 \mathrm{mg}$ TID, Tab. Haloperidol 3 mg QUI, Tab. Revocon 0.5 mg TID, Tab. Pacitane (Trihexyphenidyl). Inj. benzyl penicillin 1.2 million units every 21 days.

Chorea is a Greek word for dance. Chorea gravidarum, a hyperkinetic disorder is an uncommon condition that encompasses any cause of chorea occurring during pregnancy. Clinical manifestations include abrupt, rapid, unsustained, involuntary, purposeless, irregular and nonrhythmic movements of a limb or axial structure. ${ }^{1}$

Chorea may be unilateral hemichorea. ${ }^{2}$

Most patients with chorea gravidarum are young; the average age is 22 years. ${ }^{3}$

$80 \%$ occur during first pregnancy and $50 \%$ start during first trimester 4,5. 1/3rd begin in 2nd trimester of affected women, $2 / 3 \mathrm{rd}$ of patients it lasts till puerperium.

In pre-antibiotic era it is rare now due to decline in $\mathrm{Rh}$ fever which was a major cause of Chorea Gravidarum before. However, the scenario is different in developing countries like India where rheumatic fever still occurs frequently.

Rheumatic chorea also known as Sydenham's chorea is a delayed complication of group $A \beta$ haemolytic streptococcal infections and forms one of the major criteria of acute rheumatic fever.

In recent times, most cases of chorea appearing during pregnancy in developed countries were caused by disease entities like systemic lupus erythematosus. The oestrogen and progestational hormones may sensitize the dopamine receptors previously at stria nigra level and induce chorea in individuals who are vulnerable to this complication by virtue of pre-existing pathology in basal ganglia. Oestrogen can influence neural activity in the hypothalamus, and limbic system directly through modulation of neural excitability and they have complex multiphasic efferents on nigrostriatal dopamine receptor sensitivity. So, usage of oral contraceptives for long time may also cause chorea.

Emotional stress may also aggravate the movement of CG. The movements disappear during sleep.

Recurrence in $21 \%$ may occur in subsequent pregnancy particularly if APL is the cause. The patients may attempt to disguise chorea by incorporating it into mannerisms or gestures. Chorea movements are more distressing to observers than to individuals. A high index of suspicion and vigilance should be maintained while making a diagnosis of Chorea.

Wilson \& Preece found that the overall incidence of CG was approximately 1 case per 300 deliveries. In recent times, most cases of Chorea appearing during pregnancy are Idiopathic and rest are caused by Rheumatic, SLE, Huntington disease, APL syndrome, Wilson's disease. Many patients may give previous history of rheumatic fever and chorea. According to the case definition for rheumatic fever, documented evidence of previous streptococcal infection is found in only $20-30 \%$ of cases. Rheumatic chorea is one of the three circumstances in which the diagnosis of acute rheumatic fever can be made without strict adherence to the Jones criteria. ${ }^{6}$

Patients with Sydenham's chorea are at risk for the development of rheumatic carditis particularly mitral stenosis and to prevent this, a regimen of daily penicillin prophylaxis should be instituted and maintained. ${ }^{7}$

Of patients who present with chorea and no apparent carditis, 20\% may develop rheumatic disease after 20 years. Many patients with oral contraceptive induced chorea have a past history of chorea which in $41 \%$ of cases is rheumatic origin. ${ }^{8}$ Therapy consists of rest and seclusion careful feeding, and emotional support. Drug treatment is indicated for those with severe disabling chore or when the fetus is in danger due to dehydration malnutrition, or disturbed sleep. Death is rare. In the past, rheumatic disease was greatly the aetiology but today collagen vascular disease should also be considered. ${ }^{9}$

In our patient she had previous history of SLE and chorea which was aggravated in previous pregnancy which went unnoticed and in this pregnancy when she presented to us we diagnosed her started Tab. prednisolone $10 \mathrm{mg}$ once a day and Inj. Benzyl penicillin 1.2 million units every 21 days and tab. haloperidol and proper seclusion, rest, multivitamins and multimineral therapy.but in order to minimize risk of side effects we stopped tab. haloperidol after 4 weeks. Long acting penicillin was continued so as to prevent the risk of further progression of rheumatic heart disease and further episodes of chorea. Strict vigilance and proper diagnosis helped in our patient for further management and prevention of recurrence and patient recovered well.

\section{FINAL DIAGNOSIS}

Chorea Gravidarum Secondary to Underlying Rheumatic Heart Disease and SLE. 


\section{REFERENCES}

[1] Carapetis RJ.Acute rheumatic fever. In: Fauci AS, Braunwald E, Kasper DL, et al. eds. Harrison's Principles of internal medicine. 17th edn. McGraw-Hill Publication 2008: p. 2094-5.

[2] Dike GL. Chorea gravidarum: a case report and review. A case report and review. Md Med J 1997;46(8):436-9.

[3] Willson P, Preece AA. Chorea gravidarum. Arch Intern Med 1932;49:471-533.

[4] Gravidarum C. Report of a fatal care with neuropathological observations. Arch Neurol 1980;37(7):427-32.

[5] Ghanem Q. Recurrent chorea gravidarum in four pregnancies. Can J Neurol Sci 1985;12(2):136-8.
[6] Johnston VM. Movement disorders. In: Kliegman RM, Stanton BMD, St Geme J, et al. eds. Nelson textbook of pediatrics. $18^{\text {th }}$ edn. Philadelphia: Elsevier Publisher 2007: p. 2490-1.

[7] Sadock BJ, Sadock VA. Kaplan and Sadocks synopsis of Psychiatry. Behavioral Sciences/Clinical Psychiatry. $10^{\text {th }}$ edn. Philadelphia: Lippincott Williams \& Wilkins 2007: p. 123.

[8] Cardaro F, Seppi K, Mair KJ, et al. Seminar on choreas. Lancet Neurol 2006;5(7):589-602.

[9] Unno S, Iijima M, Osawa $M$, et al. A case of chorea gravidarum with moyamoya disease. Rhinsho Shinkeigaku 2000;40(4):378-82. 